\title{
A Differential Diagnosis of Osteolytic Lesions in the Curated Skeletal Remains of a Tantalus Monkey (Chlorocebus tantalus)
}

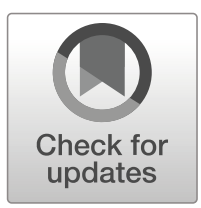

\author{
Thomas Siek $^{1} \cdot$ Cara S. Hirst $^{1,2} \cdot$ Tony Waldron $^{1}$
}

Received: 15 November 2019 / Accepted: 24 February 2020/Published online: 21 March 2020

(C) The Author(s) 2020

\begin{abstract}
In the veterinary and anthropological literature, the pathology of nonhuman primates is heavily focused on soft-tissue involvement and there is scant reference to nonhuman primates in zoopalaeopathology, the study of ancient and historical diseases in animals. We present the curated skeletal remains of a nonhuman primate present with osteolytic lesions consistent with a pathological process. We evaluated the observed pathological changes via an extensive macroscopic analysis of the skeleton, coupled with radiographic images of the affected bones, and provide a differential diagnosis of the skeletal remains using relevant clinical and zoopalaeopathological data. Multiple osteolytic lesions of varying sizes, as well as periosteal new bone, were present on several elements. The lesions affected the skeleton bilaterally, asymmetrically and with no clear focus or pattern. The skeletal lesions were differentially diagnosed as the result of either a metastatic neoplastic disease or a chronic infection. This case provides a zoopalaeopathological example for the study of skeletal lesions in nonhuman primates in anthropological and archaeological collections, where contextual data may not be available.
\end{abstract}

Keywords Differential diagnosis $\cdot$ Infection $\cdot$ Metastatic $\cdot$ Neoplasia $\cdot$ Nonhuman primate Zoopalaeopathology

\section{Introduction}

Zoopalaeopathology, a subfield of biological anthropology, is the study of ancient and historical diseases in animals and it centres on examining the skeletal remains of

Handling Editor: Joanna M. Setchell

Thomas Siek

thomas.siek.14@ucl.ac.uk

1 Institute of Archaeology, University College London, London, UK

2 Anthropology Department, University College London, London, UK 
animals for evidence of pathology. In general, the skeleton responds to external stimuli, such as trauma or pathology, in one of two ways: either through osteoblastic or osteolytic lesions. Osteoblastic lesions are characterized by new bone growth, normally consisting of periosteal new bone, which is a form of immature woven bone that does not lend to structural support (Ortner 2003; Waldron 2009). Osteolytic lesions are created through the destruction and resorption of bone and appear as holes or pitting (Ortner 2003; Waldron 2009). As a result of this limited skeletal response, zoopaleopathologists rely on considering the appearance and distribution of the observed skeletal lesions, most often via a combination of macroscopy and radiography, to construct a differential diagnosis. Numerous pathological conditions can induce a skeletal response. Some disease processes may present with pathognomonic characteristics, such as eburnation in cases of osteoarthritis (Ortner 2003; Waldron 2009); however, other diseases may result in nonspecific skeletal changes, such as osteomyelitis (Ortner 2003; Waldron 2009). Another factor that influences a skeletal reaction is the severity and character of the pathological process. For instance, an acute infection will be less likely than a chronic condition to result in observable pathological lesions (Ortner 2003; Waldron 2009). Broad pathological categories, such as infections, metabolic disorders, and neoplasms, have been established in zoopalaeopathology and these can be linked to a generalized etiology in relation to factors such as age and diet. However, it is beyond the remit of zoopaleopathology to comment on the "health" of an animal based solely on its skeletal remains. "Health" is a broad term that encompasses an individual's complete physical, mental and social well-being (World Health Organization 2020). Instead, zoopalaeopathology focuses on disease and disease processes by reporting either its presence or absence, describing how the skeleton reacted to the disease, and providing a differential diagnosis.

In zoopalaeopathology there is limited information regarding nonhuman primates. Currently, Lovell's (1990a) volume on illness and injury in great apes appears to be the only in-depth research using skeletal material, but it is questionable if the findings from this investigation can be applied across all nonhuman primates owing to differences in immune response and biology (Barreiro et al. 2010). The veterinary and anthropological literature are also challenging from a zoopalaeopathological perspective as these sources are concerned with living or recently deceased nonhuman primates (Abee et al. 2012). Thus, heavy focus is placed on soft-tissue analysis, especially histology and blood screening, as well as observed associated symptoms. Both of these forms of clinical evidence are not applicable in a zoopalaeopathological context. Instead, zoopalaeopathology must combine the veterinary and anthropological lines of enquiry with human palaeopathology. We present the curated remains of a nonhuman primate, OW.14, which exhibits numerous pathological lesions throughout the skeleton. The skeleton is part of the Biological Anthropology Collection held in the Anthropology Department at University College London, United Kingdom. The collection largely comprises hominins and other primate fossil casts, nonhuman primate skeletons, and film reels. The collection began in the early $20^{\text {th }}$ century in the Anatomy Department and was later transferred to the Anthropology Department in 1948. In 1983, the collection was greatly expanded with the donation of John Napier's personal collection of primate skeletons and fossil casts (Aiello and Ellis 1985). According to written records from the collections, OW.14 was acquired from London Zoo; however, 
when contacted, London Zoo had no records of any species being provided to John Napier. Contextual information regarding the individual's provenance, curation, or life history were missing from the collection's records. Our aim is to analyse the observable skeletal lesions and construct a differential diagnosis for this nonhuman primate. This exercise in zoopalaeopathology also serves as a methodological example for primatologists if they are presented with pathologically altered skeletal remains of a nonhuman primate.

\section{Methods}

We evaluated the osteolytic lesions via a differential diagnosis, using a combination of palaeopathological, veterinary, and anthropological enquiry. Our primary evaluative framework for analyzing the observed pathological changes was a comprehensive macroscopic analysis of the skeleton, coupled with a radiographic examination of the affected bones. Our photographs were taken with a Canon EOS 70D, with a $50 \mathrm{~mm}$ macro lens. We classified areas of periosteal new bone using schemes developed by Edeiken et al. (1966, 1981) and Ragsdale et al. (1981).

\section{Ethical Note}

There were no ethical considerations, as the focus of this investigation consists entirely of curated skeletal remains.

Data Availability All data generated or analyzed during this study are included in the present report.

\section{Results}

The skeletal remains of OW.14 were recorded as a tantalus monkey (Chlorocebus tantalus), based on macroscopic analysis of cranial and postcranial morphology. The individual is an adult based on the complete fusion of the epiphyses and complete dental eruption, although the exact age and sex could not be determined owing to a lack of published age and sex estimation methods suitable for this species. Preservation of the remains was very good and there was minimal postmortem damage to the surface of the bones. The skeleton was almost complete, apart from the missing left arm and right forearm (Fig. 1).

Multiple osteolytic lesions of varying size were present on several skeletal elements, including the cranium, vertebrae, ribs, os coxae, and fore- and hind limbs. The lesions were circular in shape and the mean diameter was $3 \mathrm{~mm}$; some coalesced into larger lesions, measuring 8-16 mm. Although little was known about the context and curation of the remains, damage resulting from cleaning the remains may have exaggerated the lesions, particularly among the smaller bones. However, the smooth edges on the osteolytic lesions, cortical involvement and areas of periosteal new bone growth 


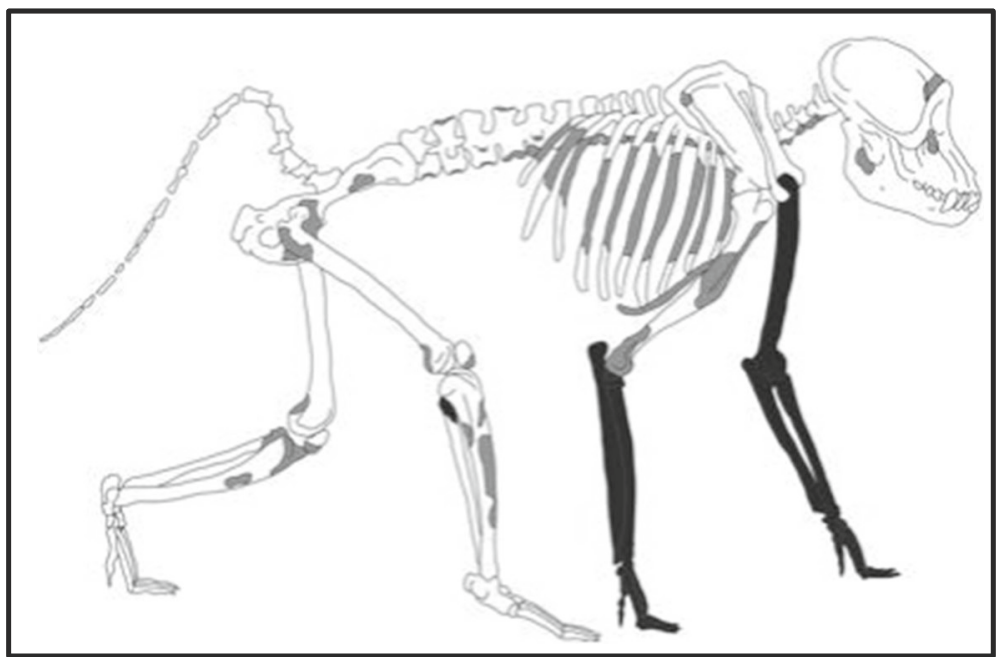

Fig. 1 A schematic diagram of the skeletal remains of OW.14, a tantalus monkey, from the Biological Anthropology Collection at University College London, UK. Missing skeletal elements are presented in black. Pathological lesion distribution is presented in gray.

indicated they were not solely the result of postmortem damage. In some cases, periosteal new bone was present adjacent to the osteolytic lesions. In comparison to the schemes for describing periosteal new bone growth (Edeiken et al. 1966; Edeiken 1981; Ragsdale et al. 1981), the lesions were most consistent with solid, continuous, thin undulating periosteal new bone formation.

There was no clear focus or pattern in the locations of the lesions and skeletal elements involved. Lesions were present on the axial skeleton and the limbs, without notable differences between or within limbs, although this may have been obscured because of the missing forelimb elements. The lesions affected the skeleton bilaterally and asymmetrically. Since the lesions were destructive to the cortical bone, all of the lesions were externally evident during the macroscopic analysis. Although there were some minor differences in the appearance of the lesions, this was likely due to the architecture of the bone, such as a long bone of the limbs versus a flat bone of the cranium, as well as biological factors, such as blood flow.

In the axial skeleton, multiple small osteolytic foci were present on the cranium, inferior to the orbital margin and on the inferior surface of the orbit (Fig. 2). On the mandible, lesions were present on the right ramus and medial surface of the corpus near the mandibular foramen. Lesions were also present on the majority of the vertebrae, including the $2-3^{\text {rd }}$ cervical, $1-7^{\text {th }}$ and $9-10^{\text {th }}$ thoracic, and all lumbar vertebrae. Similar lesions were present on 8 of the right ribs and 11 of the left; these occurred on the rib heads and the caudal surface of the mid-rib. Pathological lesions were also present on the sternum, most prominently on the manubrium, where there was some new bone growth; these lesions, which penetrated the cortex, reduced bone mass and made the sternum susceptible to damage (Fig. 3). Further osteolytic lesions were present on the os coxae, concentrated around the acetabulum and on the left and right wings of the sacrum. Together, there was a greater amount of periosteal new bone growth on the os coxae than other skeletal regions (Fig. 4). Smooth plaques of periosteal new bone 


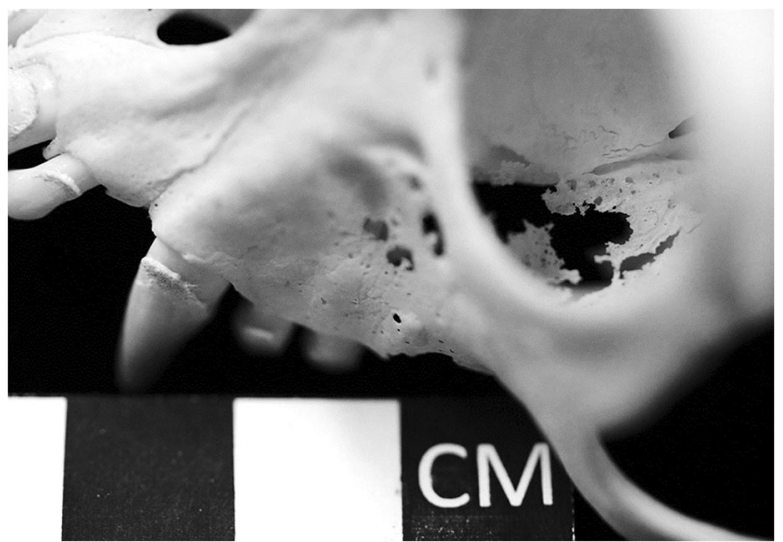

Fig. 2 The cranium of OW.14, a tantalus monkey, from the Biological Anthropology Collection at University College London, UK. Osteolytic lesions are clearly visible inferior to the orbital margin and on the interior inferior surface of the orbit.

growth were present on the pubis and ilia. The majority of periosteal new bone projected away from the surface of the bone in small spicules.

In the appendicular skeleton, osteolytic lesions were present on the lateral posterior surface of the left clavicle and the right scapula along the inferior medial border of the scapular wing. Radiographs of the humerus, ulna, and radius showed several large osteolytic foci that had not yet penetrated the cortex; these foci were predominantly located on the epiphyses and distal and proximal ends of the diaphyses (Fig. 5). On the femora, osteolytic lesions were present on the right greater trochanter, the left lesser trochanter, and on both the distal and proximal epiphyses. Adjacent to these lesions, periosteal new bone growth was also present. The osteolytic foci on the femors were small and circular in shape.

\section{Discussion}

The skeletal remains of OW.14 presented with multiple osteolytic lesions, as well as some periosteal new bone formation. There are a number of etiological causes for such lesions, including infection, neoplastic and metabolic disease, as well as trauma. A metastatic neoplastic disease or a chronic infection may be the most likely etiology for the observed skeletal lesions based on the differential diagnosis.

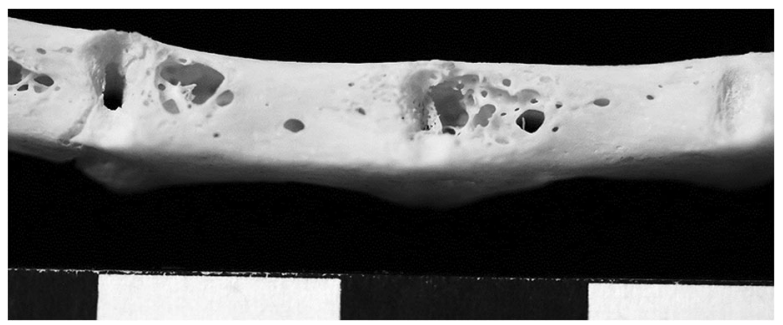

Fig. 3 The sternum of OW.14, a tantalus monkey, from the Biological Anthropology Collection at University College London, UK, with visible osteolytic lesions permeating the cortex of the sternal body. 


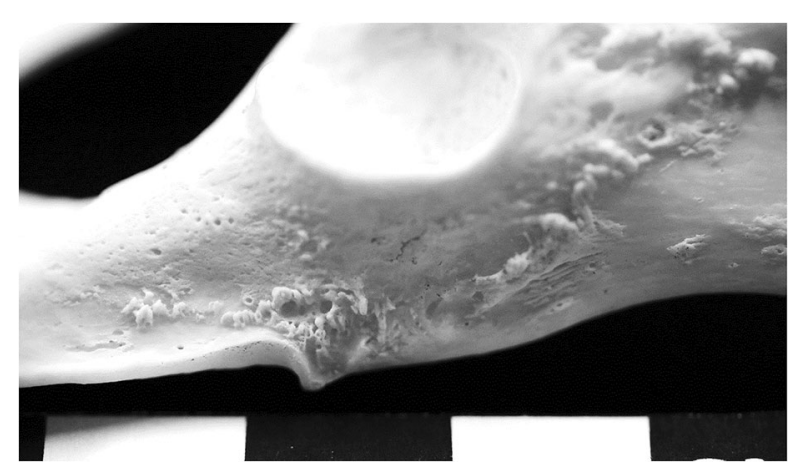

Fig. 4 The left os coxae of OW.14, a tantalus monkey, from the Biological Anthropology Collection at University College London, UK, with periosteal new bone growth.

\section{Infection}

There have been few reported cases of skeletal lesions in nonhuman primates due to infection, possibly because of the character of nonhuman primate groups (Hirst and Waldron 2019; Lovell 1990a, b; Lovell et al. 2000). Their transmission in nonhuman primate groups is limited, as many infections are reliant on poor sanitation or on large populations (Lovell 1990a, b; Lovell et al. 2000). Moreover, in the veterinary and anthropological literature, cases of infection do not include reference to skeletal lesions, and as a result, reliance must be placed on the human palaeopathological literature.

Tuberculosis is one of the few infectious diseases that both (1) affect the skeleton and (2) occur in nonhuman primates (Lignereux and Peters 1999; Parrott 2018). In human skeletal remains, the disease most often affects the vertebral column,

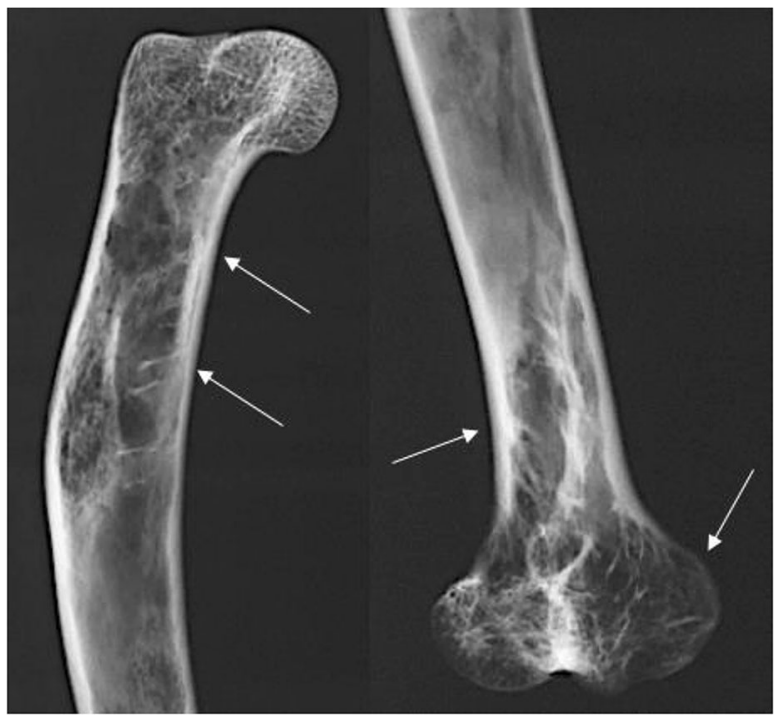

Fig. 5 Radiographs of the left distal and right proximal humerus of OW.14, a tantalus monkey, from the Biological Anthropology Collection at University College London, UK, displaying large osteolytic foci. 
particularly the bodies of the lumbar vertebrae, and results in osteolytic lesions without new bone formation (Waldron 2009). Advanced cases are characterized by weakening of the vertebral bodies, collapse, and ankylosis of the spine (Waldron 2009). Tuberculosis was once common in nonhuman primates, especially in the 1950 s when large numbers of monkeys, mainly macaques, were imported from India, but incidence declined with the adoption of faster shipping and housing the animals in more hygienic conditions (Simmons and Gibbons 2012). In nonhuman primates, the clinical presentation of tuberculosis includes a decrease in locomotion, a propensity for the long bones to bend or fracture, marked thickening of the maxilla and mandible, as well as kyphosis of the lower thoracic and upper lumbar vertebrae (Pritzker and Kessler 1998; Woodard and Montgomery 1979). However, specific osseous lesions resulting from tuberculosis appear to be rare in nonhuman primates (Fox et al. 1974; Kennard 1941; Martin et al. 1968). For example, 73 of 246 autopsied monkeys had tuberculosis but only one exhibited ankylosis with the collapse of the thoracic vertebra (Kennard 1941). In another report, one of 100 macaques was diagnosed during life with tuberculosis. At autopsy, the individual displayed a kyphosis of the lower thoracic spine, as well as osteolysis and collapse of the $10^{\text {th }}$ vertebrae; this was the only reported case that was noted to have a small zone of periosteal new bone formation (Martin et al. 1968). A third report described the autopsy of a rhesus monkey that displayed the collapse and complete destruction of the second lumbar vertebrae, resulting in a kyphosis of the upper lumbar vertebrae (Fox et al. 1974). OW.14 did have vertebral osteolytic lesions, but there were no signs of kyphosis and the observed lesions were not limited to the vertebrae, as noted in previous reports of tuberculosis in nonhuman primates (Fox et al. 1974; Kennard 1941; Martin et al. 1968). Periosteal new bone formation in relation to tuberculosis in nonhuman primates has been reported only once in the clinical literature, for one individual, by Martin et al. (1968), and thus it cannot be perceived as a diagnostic factor, as this would be highly speculative.

Other infections that could be considered are melioidosis, salmonella, and coccidioides, all of which are bacterial or fungal infections and are associated with osteomyelitis principally affecting the vertebrae (Castleman et al. 1980; Fritz et al. 1986; Klumpp et al. 1986; Rosenberg et al. 1984; Simmons and Gibbons 2012). While these infections have been previously reported among nonhuman primates, skeletal involvement is rare. For instance, five cases of melioidosis was reported in three separate outbreaks, but none of the individuals displayed evidence of skeletal lesions (Kaufmann et al. 1970).

\section{Neoplastic Disease}

In humans, metastatic skeletal lesions from soft-tissue cancers can present as osteolytic, osteoblastic, or a mix of the two (Waldron 2009). These lesions occur anywhere in the skeleton, but occur mainly in the skull, pelvis, vertebrae, scapulae, and the proximal femora (Coleman 2006). Metastases vary in their pattern and this is influenced by molecular and cellular biological characteristics of the tumor cells, as well as the tissues to which they travel; other factors affecting metastatic spread include vascular pathways, blood flow, and capillary structure (Coleman 2001). OW.14 exhibits osteolytic lesions in the axial skeleton, similar to metastasis. These lesions are accompanied by sporadic periosteal new bone formation and are asymmetrically distributed throughout 
the skeleton. While metastasis appears a possible option of the differential diagnosis, there is no contextual information for OW.14 during its life, and so nothing can be said about possible primary soft-tissue cancer sites. There is also scant information in the anthropological and zoopalaeopatholological literature regarding the manifestation of metastatic lesions in nonhuman primate skeletons. A pituitary carcinoma eroded the base of the skull in a baboon and a gibbon, diagnosed with adenocarcinoma of the pancreas, exhibited hypertrophic osteoarthropathy as a secondary complication of the neoplasm (Goodhart 1885; Ryder-Davies and Hime 1972). In the veterinary literature, the most frequent malignancies in all monkey species are lymphoma, leukemia, and cancers of the digestive tract (Lapin and Yakovleva 2014). Moreover, while gastrointestinal tumors are more frequent in macaques, this type of cancer is infrequent and usually benign among other Old World monkeys, such as the tantalus monkey (Valverde et al. 2000).

\section{Metabolic Disease}

Metabolic diseases have been reported among nonhuman primates and they can present with skeletal involvement (Morgan and Eisele 1992; Nerlich et al. 1993). One such metabolic disorder, primary hyperparathyroidism, is due to a tumor on the parathyroid gland, while secondary hyperparathyroidism is associated with renal or nutritional disease processes, such as a deficiency in vitamin D, calcium, or phosphorus (Liu 2002; Waldron 2009). The parathyroid gland produces parathyroid hormone, which stimulates osteoclasts to resorb bone and results in radiographic, cystic endocortical erosive lesions, as well as deformities in the long bones, face, and mandible (Liu 2002; Pritzker and Kessler 2012; Waldron 2009). Although osteolytic lesions are observed in OW.14, there is no deformation of the long bones; in addition, the presence of periosteal new bone is not consistent with previously reported palaeopathological lesions associated with hyperparathyroidism (Mays et al. 2001, 2007).

\section{Trauma}

Among nonhuman primates, trauma-related injuries are common, due to either accidental or nonaccidental injury, and periosteal new bone may form during healing (Jurmain 1997; Terio et al. 2011). In such cases, however, fracture lines would be observable on the bone, either macroscopically or on a radiograph, and no such lines are present on OW.14. In addition, the widely distributed nature of the lesions is inconsistent even with multiple trauma events. These observations are sufficient to discard trauma as either a proximate or distant etiology for the lesions.

\section{Conclusion}

This case report considered the character and pattern of osteolytic lesions coupled with periosteal new bone in the skeletal remains of OW.14, a tantalus monkey. However, owing to missing contextual information regarding the individual's life and the lack of references regarding the zoopalaeopathology of nonhuman primates, it is not possible to provide a specific diagnosis or to comment on the overall health status of the tantalus 
monkey. Instead, the differential diagnosis of the observed lesions considered infection, neoplastic and metabolic disease, as well as trauma. A metastatic neoplastic disease or a chronic infection may be the most likely etiology for the observed skeletal lesions.

As the anthropological and veterinary literature has been principally concerned with soft tissue, this case provides comparative material to aid in diagnosing skeletal lesions in nonhuman primates in anthropological and archaeological collections, where contextual data may not be available. This case also adds to the currently sparse zoopalaeopathological literature regarding nonhuman primates, considering the etiology and evolution of pathological processes. Finally, this case report also serves as a methodological exercise in zoopalaeopathology for primatologists if they are presented with pathologically altered skeletal remains of a nonhuman primate, either in captivity or in the field.

Acknowledgments We would like to thank Dr. Christophe Soligio and Dr. Suzanna White (Anthropology Department, UCL) for providing us access to the Biological Anthropology Collection, as well as Sandra Bond (Institute of Archaeology, UCL) for her assistance with radiography.

Author Contribution $\mathrm{CSH}$ collected the data, TS and CSH analyzed and wrote the manuscript and TW advised on the data analysis.

Open Access This article is licensed under a Creative Commons Attribution 4.0 International License, which permits use, sharing, adaptation, distribution and reproduction in any medium or format, as long as you give appropriate credit to the original author(s) and the source, provide a link to the Creative Commons licence, and indicate if changes were made. The images or other third party material in this article are included in the article's Creative Commons licence, unless indicated otherwise in a credit line to the material. If material is not included in the article's Creative Commons licence and your intended use is not permitted by statutory regulation or exceeds the permitted use, you will need to obtain permission directly from the copyright holder. To view a copy of this licence, visit http://creativecommons.org/licenses/by/4.0/.

\section{References}

Abee, C., Mansfield, K., Tardif, S., \& Morris, T. (2012). Nonhuman primates in biomedical research, Vol. 2: Diseases. London: Academic Press.

Aiello, L., \& Ellis, M. (1985). Catalogue of the biological anthropology collection incorporating the Napier Primate Collection. London: Department of Anthropology, University College London.

Barreiro, L., Marioni, J., Blekhman, R., Stephens, M., \& Gilad, Y. (2010). Functional comparison of innate immune signaling pathways in primates. PLoS Genetics, 6, e1001249.

Castleman, W., Anderson, J., \& Holmberg, C. (1980). Posterior paralysis and spinal osteomyelitis in a rhesus monkey with coccidioidomycosis. Journal of the American Veterinary Medical Association, 177, 933943.

Coleman, R. (2001). Metastatic bone disease: Clinical features, pathophysiology and treatment strategies. Cancer Treatment Reviews, 27, 165-176.

Coleman, R. (2006). Clinical features of metastatic bone disease and risk of skeletal morbidity. Clinical Cancer Research, 12, 6243s-6249s.

Edeiken, J. (1981). Roentgen diagnosis of diseases of bone (3rd ed.). Baltimore: Williams \& Wilkins.

Edeiken, J., Hodes, P. J., \& Caplan, L. H. (1966). New bone production and periosteal reaction. American Journal of Roentgenology, 97, 708-718.

Fox, J., Campbell, L., Snyder, S., Reed, C., \& Soave, O. (1974). Tuberculosis spondylitis and Pott's paraplegia in a rhesus monkey (Macaca mulatta). Laboratory Animal Science, 24, 335-339.

Fritz, P., Miller, J., Slayter, M., \& Smith, T. (1986). Naturally occurring melioidosis in a colonized rhesus monkey (Macaca mulatta). Laboratory Animals, 20, 281-285. 
Goodhart, J. F. (1885). Cancer of the pituitary body in the anubis baboon. Transactions of the Pathological Society of London, 36, 36.

Hirst, C., \& Waldron, T. (2019). Hypertrophic osteoarthropathy in an adult macaque. International Journal of Paleopathology, 25, 39-45.

Jurmain, R. (1997). Skeletal evidence of trauma in African apes, with special reference to the Gombe chimpanzees. Primates, 38, 1-14.

Kaufmann, A., Alexander, A., Allen, A., Cronin, R., Dillingham, L., et al. (1970). Melioidosis in imported non-human primates. Journal of Wildlife Diseases, 6, 211-219.

Kennard, M. (1941). Abnormal findings in 246 consecutive autopsies on monkeys. The Yale Journal of Biology and Medicine, 13, 701.

Klumpp, S., Weaver, D., Jerome, C., \& Jokinen, M. (1986). Salmonella osteomyelitis in a rhesus monkey. Veterinary Pathology, 23, 190-197.

Lapin, B. A., \& Yakovleva, L. A. (2014). Spontaneous and experimental malignancies in non-human primates. Journal of Medical Primatology, 43, 100-110.

Lignereux, Y., \& Peters, J. (1999). Elements for the retrospective diagnosis of tuberculosis on animal bones from archaeological sites. In G. Pálfy, O. Dutour, J. Deák, \& I. Hutás (Eds.), Tuberculosis past and present (pp. 339-348). Budapest: Golden Book.

Liu, S. (2002). Metabolic disease in animals. Seminars in Musculoskeletal Radiology, 6, 341-346.

Lovell, N. (1990a). Patterns of injury and illness in great apes: a skeletal analysis. Washington: Smithsonian Institution Press.

Lovell, N. (1990b). Skeletal and dental pathology of free-ranging mountain gorillas. American Journal of Physical Anthropology, 81, 399-412.

Lovell, N., Jurmain, R., \& Kilgore, L. (2000). Skeletal evidence of probable treponemal infection in freeranging African apes. Primates, 41, 275-290.

Martin, J. E., Cole, W. C., \& Whitney Jr., R. A. (1968). Tuberculosis of the spine (Pott's disease) in a rhesus monkey (Macaca mulatta). Journal of the American Veterinary Medical Association, 153, 914-917.

Mays, S., Rogers, J., \& Watt, I. (2001). A possible case of hyperparathyroidism in a burial of 15-17th century $\mathrm{AD}$ date from Wharram Percy, England. International Journal of Osteoarchaeology, 11, 329-335.

Mays, S., Brickley, M., \& Ives, R. (2007). Skeletal evidence for hyperparathyroidism in a 19th century child with rickets. International Journal of Osteoarchaeology, 17, 73-81.

Morgan, J., \& Eisele, P. (1992). Radiographic changes in rhesus macaques affected by scurvy. Veterinary Radiology \& Ultrasound, 33, 334-339.

Nerlich, A., Parsche, F., Von Den Driesch, A., \& Lohrs, U. (1993). Osteopathological findings in mummified baboons from ancient Egypt. International Journal of Osteoarchaeology, 3, 189-198.

Ortner, D. (2003). Identification of pathological conditions in human skeletal remains. London: Academic Press.

Parrott, T. (2018). Bacterial diseases of nonhuman primates. The Merck Veterinary Manual. Available from: https://www.msdvetmanual.com/exotic-and-laboratory-animals/nonhuman-primates/bacterial-diseasesof-nonhuman-primates\#v3304813 (accessed March 20, 2019).

Pritzker, K., \& Kessler, M. (1998). Diseases of the musculoskeletal system. In B. Bennett, C. Abee, \& R. Henrickson (Eds.), Nonhuman primates in biomedical research, Diseases (Vol. 2, pp. 415-459). San Diego: Academic Press.

Pritzker, K., \& Kessler, M. (2012). Arthritis, muscle, adipose tissue, and bone diseases of nonhuman primates. In C. Abee, K. Mansfield, S. Tardif, \& T. Morris (Eds.), Nonhuman primates in biomedical research, Diseases (Vol. 2, pp. 629-697). London: Academic Press.

Ragsdale, B. D., Madewell, J. E., \& Sweet, D. E. (1981). Radiologic and pathologic analysis of solitary bone lesions, part II: Periosteal reactions. Radiologic Clinics of North America, 19, 749-783.

Rosenberg, D., Gleiser, C., \& Carey, K. (1984). Spinal coccidioidomycosis in a baboon. Journal of the American Veterinary Medical Association, 185, 1379.

Ryder-Davies, P., \& Hime, J. M. (1972). Hypertrophic osteoarthropoathy in a gibbon (Hylobates lar). Journal of Small Animal Practice, 13, 655-658.

Simmons, J., \& Gibbons, S. (2012). Bacterial and mycotic diseases of nonhuman primates. In C. Abee, K. Mansfield, S. Tardif, \& T. Morris (Eds.), Nonhuman primates in biomedical research, Diseases (Vol. 2, pp. 105-172). London: Academic Press.

Terio, K., Kinsel, M., Raphael, J., Mlengeya, T., Lipende, I., et al. (2011). Pathologic lesions in chimpanzees (Pan troglodytes schweinfurthii) from Gombe National Park, Tanzania, 2004-2010. Journal of Zoo and Wildlife Medicine, 42, 597-607.

Valverde, C., Tarara, R., Griffey, S., \& Roberts, A. (2000). Spontaneous intestinal adenocarcinoma in geriatric macaques (Macaca sp.). Comparative Medicine, 50, 540-544. 
Waldron, T. (2009). Palaeopathology. Cambridge: Cambridge University Press.

Woodard, J., \& Montgomery, C. (1979). Musculoskeletal system. In Benirschke, K., Garner, F., \& Jones, T., (Eds.), Pathology of Laboratory Animals (pp. 663-887). New York: Springer-Verlag.

World Health Organization. (2020). "Constitution." Available from: https://www.who.int/about/who-weare/constitution. Accessed 8 Feb 2020. 